\title{
ENFOQUE SISTÊMICO COMO ESTRATÉGIA DE ESTUDO PARA EXPANSÃO DA INTEGRAÇÃO LAVOURA-PECUÁRIA NA REGIÃO DE GUARAPUAVA-PR
}

\author{
Regular Approach as Strategy of Study for Expansion of the \\ Farming-Cattle Integration in the Region Of Guarapuava-PR
}

\author{
Denise Bruginski de Carvalho ${ }^{1}$ \\ Márcia Bello ${ }^{2}$
}

\section{Resumo}

O objetivo deste trabalho foi acompanhar o monitoramento de diferentes áreas de integração lavourapecuária, dentro de sete propriedades agrícolas na região de Guarapuava-PR, Brasil, e observar a participação e o nível de comprometimento de agropecuaristas, técnicos e pesquisadores (professores e estudantes), envolvidos em diferentes atividades, numa pesquisa desenvolvida dentro do enfoque sistêmico. Houve diferentes níveis de comprometimento e envolvimento com a pesquisa, sendo a equipe de campo a que mais participou na coleta de dados, entretanto, as demais classes representadas por agropecuaristas, técnicos e professores demonstraram interesse nas discussões e na expansão da integração lavoura-pecuária na região de Guarapuava.

Palavras-chave: Monitoramento; Pesquisa e ação; Propriedades agropecuárias; Sistemas de produção.

\section{Abstract}

The objective of this work was to follow the monitoring of different areas of crop-cattle raising integration in seven agricultural properties in Guarapuava-PR, Brazil, and to observe the participation and the level of agriculture and crop raising compromising, technicians and researchers (teachers and students) involved in different activities in a research developed inside of the systemic focus. There were different compromising levels and involvement with the research being the field team the one that had more participation in the collection of data, however the other classes represented by agriculture and crop raising, technicians and teachers demonstrated interest in the discussions and in the expansion of the crop-cattle raising integration in Guarapuava.

Keywords: Agricultural properties; Monitorial; Production systems; Researches and action.

Eng. Agrônoma, M. Sc., aluna de doutorado. Curso de Pós-graduação em Agronomia - Produção Vegetal, UFPR, bolsista CAPES. Rua dos Funcionários, 1540, Curitiba/PR, CEP 80035-050. denisehb@agrarias.ufpr.br.

2 Eng. Agrônoma, aluna de mestrado. Curso de Pós-graduação em Agronomia - Produção Vegetal, UFPR, bolsista CAPES. agrobello@bol.com.br. 


\section{Introdução}

O Departamento de Fitotecnia e Fitossanitarismo do Setor de Ciências Agrárias da Universidade Federal do Paraná tem desenvolvido pesquisas em integração lavoura-pecuária em diversas regiões do Estado do Paraná. Os resultados obtidos mostram que esta é uma alternativa viável, de alta sustentabilidade, permitindo uma maior lucratividade aos produtores e uma considerável diminuição de insucesso do negócio agrícola.

No Paraná, até o momento, é muito pequeno o número de propriedades que utiliza a integração lavoura-pecuária. Persistem, entre os produtores e agrônomos da assistência técnica, receios sobre o efeito da entrada dos animais em áreas de lavouras, quais espécies utilizar e como manejá-las. O enfoque sistêmico disponibiliza uma análise criteriosa dos reais entraves à adoção desta tecnologia nos sistemas reais de produção e uma maior interação entre todos os agentes envolvidos: agropecuaristas, pesquisadores, extencionistas e dirigentes de cooperativas.

O objetivo deste trabalho foi acompanhar o monitoramento de diferentes áreas de integração lavoura-pecuária dentro de propriedades agrícolas na região de Guarapuava-PR e observar a participação e o nível de comprometimento de agropecuaristas, técnicos e pesquisadores (professores e estudantes) envolvidos em diferentes atividades, numa pesquisa desenvolvida dentro do enfoque sistêmico.

\section{Materiais e métodos}

Inicialmente formou-se um grupo interdisciplinar envolvendo alunos e professores da Universidade Federal do Paraná, doutores em diversas áreas (manejo de pastagens, cultivos agrícolas, manejo animal, manejo integrado de plantas daninhas, impactos ambientais, desenvolvimento de pesquisa e ação, e relacionamento interpessoal em pesquisas sistêmicas em grupos interdisciplinares), para encontros semanais e discussão do encaminhamento da pesquisa.

Foram entrevistados 27 agropecuaristas da região de Guarapuava-PR, utilizando como ferramenta um questionánio para diagnóstico rápido das principais características do itinerário técnico adotado. Esse grupo passou a ser designado como "grupo de referência" (PASSINI, 1997). A partir dos resultados obtidos, foram selecionadas sete propriedades agrícolas para serem monitoradas durante doze meses. Foram escolhidas condições contrastantes de tamanho da propriedade, histórico de produção e afinidade ou preferência pela agricultura ou pecuária, mas todas com boas condições de acesso para visitas freqüentes e facilidade de comunicação com o proprietário.

Após a seleção, os proprietários envolvidos participaram de uma reunião para esclarecimento da metodologia participativa para o desenvolvimento do trabalho.

Foi utilizada a temática do enfoque sistêmico juntamente com a abordagem interdisciplinar para ações de pesquisa e desenvolvimento reunindo os agropecuaristas, técnicos e pesquisadores em diferentes momentos: reuniões entre pesquisadores, consultas diretas com técnicos e informantes-chaves e dias de campo com a participação de agropecuaristas, técnicos e pesquisadores. Em Guarapuava foram realizadas quatro reuniões para apresentação da proposta de trabalho no enfoque sistêmico, em que participaram representantes dos alunos, professores, técnicos e agropecuaristas.

O monitoramento das sete propriedades foi realizado com visitas mensais e coletas de dados referentes ao desenvolvimento de pastagens, densidade e fertilidade do solo e nível de nitrato na solução de solo. Na primeira visita para o monitoramento foram entregues livros de registro de dados referentes aos procedimentos técnicos adotados nas áreas monitoradas, como por exemplo, a data de semeadura, quantidade de adubo e número de animais mantidos em pastejo. Neste mesmo dia foram instalados termômetros de máxima e a mínima e pluviômetros próximos da área monitorada. Foram entregues fichas para registros diários de temperatura e precipitação pluvial para 0 proprietário, que se encarregou de designar um funcionário responsável para essa tarefa.

O monitoramento de dados ocorreu em doze datas em que as equipes de campo, formadas por 21 alunos do curso de agronomia e oito alunos do curso de pós-graduação, revezaram-se no trabalho de coleta de dados. Foram coletadas 74 amostras de solo para realização de análise química de rotina, 80 amostras de solo para verificação de densidade, granulometria e construção de curvas de retenção de umidade e 881 amostras 
de solo para determinação da concentração de nitrato. Para o acompanhamento do desenvolvimento das pastagens foram coletadas 288 amostras.

A cada dois meses após o início do monitoramento de dados foram realizados dias de campo nas sete propriedades monitoradas que, com pequenas variações, seguiam a seguinte dinâmica: 1) apresentação geral da propriedade e distribuição de folheto informativo; 2) apresentação de no máximo cinco talhões, incluindo a área monitorada; 3) discussão sobre as limitações e possíveis soluções de problemas encontrados com relação à integração lavoura-pecuária; 4) confraternização do grupo; 5) discussão sobre a demanda de pesquisa.

\section{Resultados}

Foram realizadas 15 reuniões envolvendo professores e alunos da pós-graduação, para discussões conceituais e metodológicas, no início do desenvolvimento da pesquisa. Devido à constituição interdisciplinar do grupo, as freqüentes discussões conceituais ampliaram a dimensão sistêmica da pesquisa e contribuíram para 0 enriquecimento individual e coletivo, porém, mais em relação à teoria do que a prática. As idéias conflitantes com relação à metodologia do trabalho transformaram-se em empecilhos para a tomada de decisão em aspectos práticos. Por esse motivo, a freqüência das reuniões, que era inicialmente semanal, passou a ser mensal e finalmente esporádica, por consenso do próprio grupo. Ficou evidente a dificuldade de relacionamento entre os pesquisadores temáticos e sistêmicos. Ribeiro (1995) afirma que isso ocorre, em parte, porque os pesquisadores temáticos ainda não acreditam na pesquisa sistêmica, não compreendem as metodologias empregadas que não utilizam os clássicos delineamentos experimentais.

Durante o período de coleta de dados (um ano), os alunos demonstraram seriedade ao assumirem o compromisso da participação no projeto, dispostos ao trabalho de campo, independentemente das condições climáticas. As análises foram realizadas nos laboratórios da UFPR, com participação efetiva dos estagiários durante três meses consecutivos de procedimentos analíticos.

Houve várias falhas na coleta de dados de temperatura e precipitação pluvial diária, dei- xada sob responsabilidade dos proprietários, o que ocorreu também com outras informações relativas aos procedimentos técnicos adotados nas áreas monitoradas. Uma das propriedades escolhidas para o monitoramento de dados foi vendida, impossibilitando a continuidade das atividades.

Cinco dos sete proprietários envolvidos diretamente com o monitoramento de dados possuem terceiro grau completo e demonstraram, no início do trabalho, grande interesse na participação direta. Porém, ao contrário do esperado, em apenas duas propriedades houve o cuidado no registro diário dos dados e das operações realizadas na área de monitoramento. Hawkins (1995) e Salazar (1992) apontam a dificuldade de participação dos agricultores na investigação como o problema de mais difícil solução em pesquisas deste gênero e relacionam que em mais da metade dos projetos de pesquisa em sistemas analisados, a participação dos agricultores foi do tipo consultiva. Isto quer dizer que os agricultores se limitaram a responder questões e buscar solucionar problemas individuais, com o menor comprometimento possível com a coleta de dados.

Em dias de campo, os proprietários mostravam-se participativos e motivados, permitindo interação entre os membros do grupo.

Estiveram presentes nos dias de campo, além do grupo de referência e dos alunos de graduação e pós-graduação, cinco professores, sete agrônomos representando a assistência técnica particular, EMATER, IAPAR, CEDETEG, FAPA, COAMO e MONSANTO. A participação assídua dos técnicos da região demonstrou o interesse que esses apresentam em serem considerados como especialistas em integração lavoura-pecuária, principalmente em função do receio de concorrência. Houve um sério comprometimento de alguns profissionais que acompanharam todos os eventos promovidos pelo projeto.

Outros agropecuaristas que ainda não utilizam a integração lavoura-pecuária também estiveram presentes e demonstraram interesse no sistema. Foram geradas discussões envolvendo manejo animal, nutrição mineral das pastagens, compactação de solo, misturas de espécies de pastagens, rotação de culturas, manejo de plantas daninhas, relação custo benefício, qualidade da carne e oportunidades de mercado. 


\section{Considerações finais}

Houve diferentes níveis de comprometimento e envolvimento com a pesquisa, destacando-se a equipe de campo na coleta de dados. Os demais participantes demonstraram interesse nas discussões e na expansão da integração lavourapecuária na região de Guarapuava.

\section{Agradecimento}

Agradecemos à MONSANTO pelo apoio financeiro para a execução do projeto.
PASSINI, J.J. Redes de propriedades de referência. In: IAPAR. Enfoque Sistêmico em P e D: a experiência metodológica do IAPAR. Circular, 97. Londrina: IAPAR. 1997. p. 152p.

RIBEIRO, Mde F. 1995. A experiência do IAPARem validação de tecnologias. In: ENCONTRO DA SOCIEDADE BRASILEIRA DE SISTEMAS DE PRODUÇÃO. 2., Londrina, 1995. Anais... Londrina: SBSP, 1995. p. 53-63.

SALAZAR, L. La accion comunicativa como complementacion al enfoque de sistemas. Revista Investigacion Desarrollo para América Latina, FONAIAP/CIRAD, v. 1, p. 68-75. 1992.

\section{Referências}

Recebido 12/05/2003

HAWKINS, R. 1995. Colaboración y participación Aprovado 30/09/2003 en la IESA. In: ENCONTRO DA SOCIEDADE BRASILEIRA DE SISTEMAS DE PRODUÇÃO. 2., Londrina, 1995. Anais... Londrina: SBSP, 1995. p. 1-20. 